\title{
CHIRAL 2-ALKYLBRANCHED ACIDS, ESTERS AND ALCOHOLS. PREPA- RATION AND STEREOSPECIFIC FLAVOUR EVALUATION
}

\author{
Klaus Rettinger a), Christian Burschka b), Peter Scheeben a), Heike Fuchs a), and Armin Mosandl ${ }^{* a)}$ \\ Institut für Lebensmittelchemie der Universitāt Frankfurt, Robert-Mayer-Straße 7-9, D-6000 Frankfurt am Main, Germany a) \\ Institut für Anorganische Chemie der Universitāt Würzburg, Am Hubland, D-8700 Wūrzburg, Germany b)
}

(Received 24 July 1991)

Key words: 2-alkylbranched acids, esters and alcohols; flavour substances; chirality and odour

\begin{abstract}
Racemic 2-alkylbranched acids are transformed to diastereomeric derivatives with (S)-2-hydroxy-3-phenylpropionic acid-N-methylamide or (S)-(-)-1-phenylethylamine and separated by liquid chromatography to pure diastereoisomers, which are subsequently hydrolyzed to yield optically pure acids. Enantiomeric alcohols are generated by LiAlH $_{4}$ reduction of the corresponding acids, esters are synthesized by different methods. The odour impression of the enantiomeric compounds is investigated.
\end{abstract}

2-Alkylalkanoic acids, esters and alcohols are well appreciated aroma compounds of fruits and other foodstuffs 1). In particuliar 2-methylbutanoic acid and its esters are known to be important compounds of fruits like apples ${ }^{2}$ ) and pineapples ${ }^{3}$ ). Until now odour quality only was investigated with racemic substances of this type, although it is generally known that enantiomers may exhibit rather different odour sensations ${ }^{4)}$. 2-Alkylbranched acids and alcohols are important for pheromone synthesis and liquid crystal investigations, too. Recently, investigations on lipase-catalyzed enantioselective esterification of 2methylalkanoic acids have been reported by Engel5).

This paper now describes the generation of optically pure 2-methylbutanoic acid (1), 2-methylpentanoic acid (2) 2-methylhexanoic acid (3), 2-ethylhexanoic acid (4), the corresponding alcohols 2-methyl-butan-1ol (5), 2-methyl-pentan-1-ol (0), 2-methyl-hexan-1-ol (7), 2-ethyl-hexan-1-ol (8) and the esters ethyl-2methylbutanoate $(9)$ and prenyl-2-methylpentanoate (10).

In order to determine their absolute configurations racemic acids 1-4 were converted to diastereomeric amides with (S)-(-)-1-phenylethylamine (SPEA) and chromatographically (LC) separated into optically pure diastereoisomers. Diastereomeric amides were prepared either by a way earlier described by Kaneda ${ }^{6}$ ) with equimolar ratio of free acid and free amide by catalysis of $\mathrm{N}, \mathrm{N}^{\prime}$-Dicylclohexylcarbodiimide (DCC) in dry tetrahydrofurane (THF) or by an other way versus acid chloride and free amine under catalysis of 4-Dimethylaminopyridine (DMAP). Absolute configurations of the 2-alkylalkanoic acids moieties were eludicated by comparison with easily available (S)-2-methylbutanoic acid $1 a$ and by ${ }^{1} \mathrm{H}-\mathrm{NMR}$ data of their diastereomeric (S)-1-phenylethylamides?) (Helmchen's model), by chromatographic behaviour of these 
amides in LC according to Helmchen et al. ${ }^{8)}$ and by comparison with gas chromatographic data from Sonnet ${ }^{9)}$ [For ${ }^{1} \mathrm{H}-\mathrm{NMR}$ data of relevant shift of the two acyl- $\mathrm{CH}_{3}$-groups see table 1 , in LC on silica gel (R)-acid-SPEA eluted before (S)-acid-SPEA, in gas chromatography on Carbowax $20 \mathrm{~m}$ and DB 5 stationary phase (S)-acid-SPEA eluted prior to (R)-acid-SPEA].

Table 1: Characteristic ${ }^{1} \mathrm{H}-\mathrm{NMR}$-data (Acyl- $\mathrm{CH}_{3}$-signals, $\delta$-values, [ppm]; $300 \mathrm{MHz}, \mathrm{CDCl}_{3} / \mathrm{TMS}$ ) of diastereomeric (S)-1-phenylethylamine-derivatives of 2-alkylbranched acids used for the determination of the absolute configuration<smiles>CCCCCCC(CC)C(=O)NC(C)c1ccccc1</smiles>

\begin{tabular}{|l|l|l|l|l|l|l|l|l|}
\hline $\begin{array}{l}\text { absolute } \\
\text { configuration }\end{array}$ & \multicolumn{2}{|c|}{$\begin{array}{c}(1) \\
\mathrm{m}=0 ; \mathrm{n}=1\end{array}$} & \multicolumn{2}{c|}{$\begin{array}{c}\text { (2) } \\
\mathrm{m}=0 ; \mathrm{n}=2\end{array}$} & \multicolumn{2}{c|}{$\begin{array}{c}\text { (3) } \\
\mathrm{m}=0 ; \mathrm{n}=3\end{array}$} & \multicolumn{2}{c|}{$\begin{array}{c}\text { (4) } \\
\mathrm{m}=1 ; \mathrm{n}=3\end{array}$} \\
\hline acyl-group & $\mathrm{a}-\mathrm{H}$ & $\mathrm{b}-\mathrm{H}$ & $\mathrm{a}-\mathrm{H}$ & $\mathrm{b}-\mathrm{H}$ & $\mathrm{a}-\mathrm{H}$ & $\mathrm{b}-\mathrm{H}$ & $\mathrm{a}-\mathrm{H}$ & $\mathrm{b}-\mathrm{H}$ \\
& $\mathrm{t} ; 3 \mathrm{H}$ & $\mathrm{d} ; 3 \mathrm{H}$ & $\mathrm{t} ; 3 \mathrm{H}$ & $\mathrm{d} ; 3 \mathrm{H}$ & $\mathrm{t} ; 3 \mathrm{H}$ & $\mathrm{d} ; 3 \mathrm{H}$ & $\mathrm{t} ; 3 \mathrm{H}$ & $\mathrm{t} ; 3 \mathrm{H}$ \\
\hline & & & & & & & & \\
& 0,86 & 1,14 & 0,87 & 1,14 & 0,84 & 1,14 & 0,82 & 0,91 \\
$\mathrm{~S}$ & 0,91 & 1,11 & 0,91 & 1,11 & 0,89 & 1,12 & 0,90 & 0,82 \\
$\mathrm{R}$ & &
\end{tabular}

The optically pure amides were hydrolyzed $(1: 1 / \mathrm{v}+\mathrm{v}$; mixture of $25 \% \mathrm{HCl} /$ glacial acetic acid, $8-15 \mathrm{~h}$, $110^{\circ} \mathrm{C}$ ) to yield optically active acids $1-4$. Optical purity was not in all cases $100 \%, 2$-methylbutanoic acid and especially 2-ethylhexanoic acid interconverted slightly during hydrolysis of the amides.

In order to prepare optically pure 2-methylbutanoic acid (1), 2-methylpentanoic acid (2) and 2ethylhexanoic acid (4) the chiral auxiliary (S)-2-hydroxy-3-phenylpropionic acid-N-methylamide was used. Diastereomeric (S)-2-[2-alkylalkanoyloxy]-3-phenylpropionic acid- $\mathrm{N}$-methylamides were separated by LC and subsequently hydrolyzed with a small excess of alkali to yield optically pure 2-alkylbranched acids ${ }^{10}$ ). Diastereomeric derivatives of this type were synthesized under DMAP-catalysis by the reaction of an equimolar ratio of the acid chloride of racemic 2-alkylakanoic acid with (S)-2-hydroxy-3-phenylpropionic acid in dry methylene chloride. After isolation the (S)-2-[2-alkylalkanoyloxy]-3-phenylpropionic acid was treated with oxalylchloride. The resulting acid chloride reacted with a $33 \%$ solution of methylamine in dry ethanole (Fluka). After purification diastereoisomers were separated by liquid chromatography on silica gel, to yield optically pure acids alkalic hydrolysis was performed $(1.1 \mathrm{~mol}$ excess of $\mathrm{KOH}$ in dist. water after solution of the derivative in acetone, stirring $5 \mathrm{~h}$ at room temperature, extraction after acidification).

The absolute configurations of this acids were assigned via the corresponding (S)-1-phenylethylamides ${ }^{7-9)}$. The optical purity control of the free acids was performed by capillary gas chromatography (CGC)-analysis on heptakis(2,3,6-tri-O-methyl)- $\beta$-cyclodextrin (permethyl- $\beta$-cyclodextrin) or heptakis-

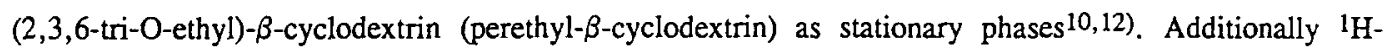
NMR-spectroscopy was applied, analoguously to the model of Helmchen for (S)-(-)-1-phenylethylamides 7 . All acids were chemically purified by LC on silicagel with a pentane/diethylether-gradient ${ }^{10}$ ). 
Table 2: ${ }^{1} \mathrm{H}$-NMR-data (Acyl- $\mathrm{CH}_{3}$-signals, $\delta$-values, [ppm]; $300 \mathrm{MHz}, \mathrm{CDCl}_{3} / \mathrm{TMS}$ ) of diastereomeric (S)-2-hydroxy-3-phenylpropionic acid derivatives of 2-alkylbranched acids used for the

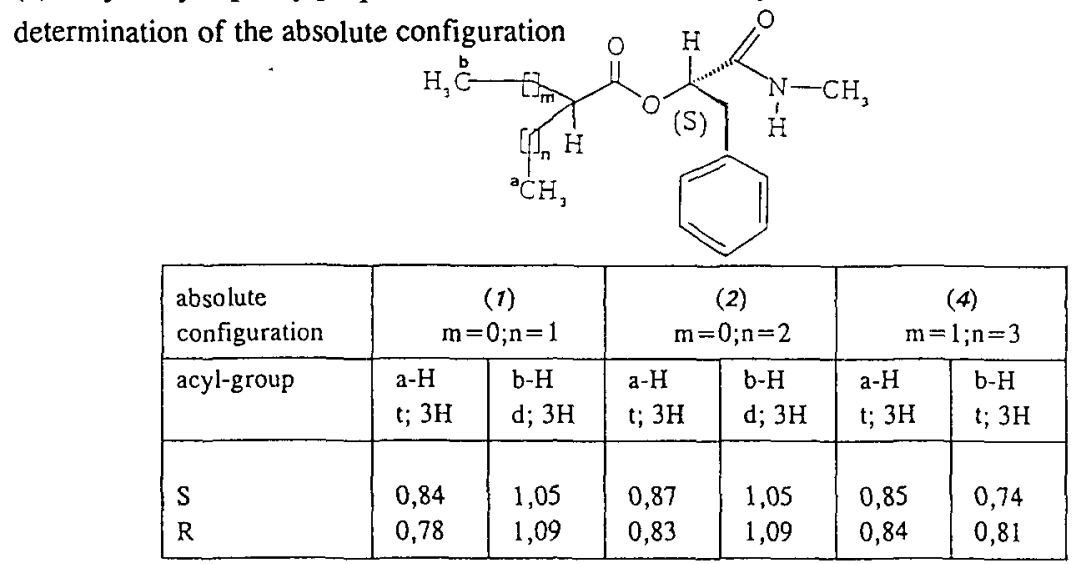

An X-ray structural analysis ${ }^{11)}$ was made of (S)-2-[(R)-2-methylpentanoyloxy]-3-phenylpropionic acid-Nmethylamide (11) (fig. 1).

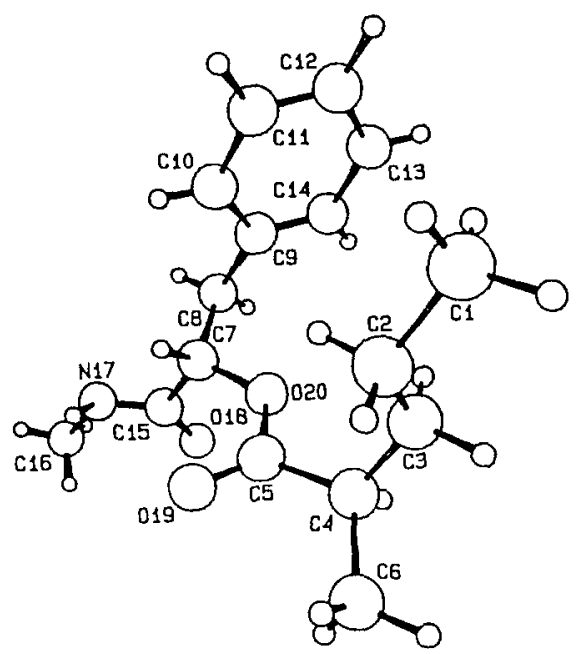

Figure 1. Molecular structure of

$(S, R)-11$. Selected bond distances

$(\AA)$ and angles $\left(^{\circ}\right)$ for the molecoule

shown are as follows: 018-C15

1.225(8), 019-C5 1.194(8), O20-C5

$1.353(7), \mathrm{O} 20-\mathrm{C} 71.435(7), \mathrm{C} 4-\mathrm{CS}$

1.52 (1), C4-C6 $1.51(1), \mathrm{C} 7-\mathrm{C} 8$

$1.531(8), \mathrm{C} 7-\mathrm{C} 151.522(8) \AA$,

C5-O20-C7 114.8(5),

C3-C4-C5 109.91(7),

C3-C4-C6 116.9(8),

$\mathrm{O} 20-\mathrm{C} 5-\mathrm{C} 4$ 110.9(6),

O20-C7-C8 106.7(5),

O20-C7-C15 110.2(5),

C8-C7-C15 110.7(5)

As outlined in table 3 rather different odour qualities of enantiomers (optical purity $>98 \%$ ee) were found. It can be observed that the odour of (S)-2-methylbutanoic acid is similiar to that one of (R)-2-methylpentanoic acid, while the corresponding enantiomers show different odour qualities. It is known that (S)-2methylbutanoic acid and (S)-2-methyl-butan-1-ol are found in natural food in a high excess ${ }^{10}$ ). About the absolute configuration of the other 2-alkylalkanoic acids, esters and alcohols in food nothing is known until now.

Alcohols were made by reduction of the chemically purified acids with $\mathrm{LiAlH}_{4}$. For odour of chiral alcohols see table 3 . A control of optical purity is possible by gas chromatography on perethylated $\beta$ cyclodextrin phase 10,12 ).

Esters were made in different ways. Prenyl (3-methyl-2-buten-1-yl) esters of 2-methylpentanoic acid, whose odour has been described as black currant-like ${ }^{13)}$, were synthesized via acid chlorides of optically 
pure (R)- and (S)- 2-methylpentanoic acid. A slight interconversion (enantiomer distribution 90:10) was observed. Optically pure ethyl-2-methylbutanoates were prepared via the potassium salts of 2methylbutanoic acid $(1 \mathrm{mmol})$ with ethyliodid $(5 \mathrm{mmol})$ in dry dimethylformamide $(7,5 \mathrm{ml})$ according to Mosandl 14). For sensory description of the esters, see table 3; optical purity control of ethyl-2methylbutanoates was carried out by CGC on perethylated $\beta$-cyclodextrin-phase 12 ).

Table 3: Odour of the investigated enantiomers

\begin{tabular}{lll} 
Substance & (R)-enantiomer & (S)-enantiomer \\
\hline 1 & penetrating cheesy-sweaty note & pleasant sweet, fine fruit note \\
2 & pleasant sweet, fruit note & sweet, pungent, heavy \\
3 & sweet, sweaty & sour, pungent, musty \\
4 & herbaceous-earthy & sweet-herbaceous, mild musty \\
5 & pleasant, earthy musty & pungent, etheric fruity \\
6 & etheric, musty & first bloomy, then earthy musty \\
7 & violetlike, bloomy-sweet, heavy & sweet, some bloomy with musty note \\
8 & heavy, earthy, some bloomy note & light, sweet bloomy odour \\
9 & first medical-phenolic note, & etheric, sweety, unspecific, pleasant \\
& then fruity-sweet but unspecific & apple note at extreme dilution \\
10 & musty, sweety, fruity, weak & reminiscent of black currant \\
& chemical & \\
\hline
\end{tabular}

\section{References and Notes}

1) H. Maarse, C.A. Visscher, Volatile Compounds in Food, Qualitative and Quantitative Data, Vol. I-III., , CIVO-TNO, Zeist, the Netherlands (1989) and references cited therein.

2) R.A. Flath, D.R. Black, W.H. Guadagni, W.H. McFadden, T.H. Schultz, J. Agric Food Chem. 15 (1967) 29.

3) H. Ohta, S. Kinjo, Y. Osajima, J. Chromatogr. 409 (1987) 409.

4) G. Ohloff, Experientia 42 (1986) 271.

5) K.-H. Engel, Tetrahedron Asymm. 2 (1991) 165

6) T. Kaneda, J. Chromatogr. 366 (1986) 217.

7) G. Helmchen, Tetrahedron Lett. (1974) 1527.

8) G. Helmchen, H. Völter, W.Schühle, Tetrahedron Lett (1977) 1417.

9) P.E. Sonnet, A.T. Proveaux, E. Adamek, H. Sugie, R. Sato, Y. Tamaki, J. Chem. Ecol. 13 (1987) 547.

10) K. Rettinger, Chirale Fruchtaromastoffe - 2-alkylverzweigte Sãuren, Ester und Alkohole, doctoral thesis Univ. Frankfurt (1991).

11) Crystal data: $11, \mathrm{O}_{3} \mathrm{NC}_{16} \mathrm{H}_{23}$, monoclinic, space group $\mathrm{P} 21, \mathrm{a}=9.302(2) \quad \mathrm{b}=9.332(2) \quad \mathrm{c}=9.550(2) \quad \beta=$ $95.02(2) \mathrm{V}=825.8 \AA^{3},\left(Z=2\right.$, density $\left.=1.76 \mathrm{mg} / \mathrm{mm}^{3}\right)$, MoK $\alpha$-Strahlung, $\lambda=0.70930 \AA$, Graphit-Monochromator, $\omega \theta$-Abtastung). Of 1647 measured intensities 1451 were considered observed $\left(\mathrm{I}_{\mathrm{obs}}>3 \sigma\left(\mathrm{I}_{\mathrm{obs}}\right)\right.$ ). The use of direct methods to the received data (SHELXS86) allowed to solve the structure. Subsequent refinement (least-squares) afforded $R_{1}$ and $R_{2}$-values of 0,049 and 0,043 respectively. Complete data have been deposited at the Fachinformationszentrum Energie, Pbysik, Mathematik, D-7514 Eggenstein-Leopoldshafen 2; deposition No. CSD 55599.

12) K. Rettinger, V. Karl, H.-G. Schmarr, F. Dettmar, U. Hener, A. Mosandl, Phytochem. Anal. (1991), in press.

13) R.D. Schmid, Fette, Seifen, Anstrichmittel 88 (1986) 555.

14) A. Mosandl, Struktur und Geruch substituierter Glycidsãureester, Habilitationsschrift Würzburg (1981), p. 111. 